\title{
A Review of the Current Status of Bamboo Usage with Special Emphasis on Orthopedic Rehabilitation
}

\author{
Aruoture Egoh ${ }^{1}$, Kischa S. Reed ${ }^{2}$, Peter N. Kalu ${ }^{1}$ \\ ${ }^{1}$ Department of Mechanical Engineering, FAMU-FSU College of Engineering, Tallahassee, FL, USA \\ ${ }^{2}$ Division of Physical Therapy, Florida A\&M University, Tallahassee, FL, USA \\ Email: aruoture1.egoh@famu.edu
}

How to cite this paper: Egoh, A., Reed, K.S. and Kalu, P.N. (2020) A Review of the Current Status of Bamboo Usage with Special Emphasis on Orthopedic Rehabilitation. Materials Sciences and Applications, 11, 415-430.

https://doi.org/10.4236/msa.2020.117028

Received: December 5, 2019

Accepted: July 7, 2020

Published: July 10, 2020

Copyright $\odot 2020$ by author(s) and Scientific Research Publishing Inc. This work is licensed under the Creative Commons Attribution International License (CC BY 4.0).

http://creativecommons.org/licenses/by/4.0/

\begin{abstract}
It was found that bamboo has been extensively used as infrastructure material in Asia and Africa due to its exceptional properties. Its usage has ranged from simple fence construction to bridges. Bamboo, as a biodegradable and renewable material, has been used for construction purposes. Both the natural and engineered form of the Bamboo has become a center of focus for most research scientists, materials experts and most important research and development aspects of Industries. The physical and mechanical properties of Bamboo culm in its dry and green state have shown promising prospects and this has further established the need to put together a regulatory body that will help to monitor and create standards for testing and utilizing Bamboo. This paper considered the various applications of Bamboo culm both in the past and present. An area the authors considered in this paper is the use of Bamboo in orthopedics. The number of people with gait dysfunction is fast growing due to population growth, war, ageing and accidents. The cost of orthopedic devices essential to restore function and improve quality of life is not affordable for many. Earlier research in this area suggests that bamboo is a suitable material for orthopedic appliances, especially exoskeleton. Bamboo use in applications such as orthopedic rehabilitation is common in developing countries where traditional bonesetters (TBS) use splints to treat fracture. In spite of the innovative discovery made by researchers in the use of Bamboo, standardization is a major challenge especially in orthopedic application. The focus of our work revealed varieties of Bamboo application.
\end{abstract}

\section{Keywords}

Bamboo, Orthopedic Device, Construction, Rehabilitation, Exoskeleton 


\section{Introduction}

The advantages of Bamboo usage in its green and dry form is becoming an area of interest to researchers and materials scientist. Because of its renewability and biodegradability, Bamboo plant has been considered in various applications. Its properties are far superior when compared to wood and other natural materials. Some physical and mechanical properties of Bamboo are comparatively close to those of steel, and in applications where low density and specific gravity are most important. There is growing interest in the research and development of Bamboo products as a sustainable, cost effective and ecologically responsible alternative material for construction. Bamboo often known as the "Green gold" of the forest [1] has over 1250 species in the world [2]. India is said to have the largest land mass on which Bamboo is grown.

The properties of Bamboo are dependent on the radial, transverse and longitudinal direction making it an anisotropic material. These properties are dependent on the age, moisture content, species and the part of the Bamboo used; the nodes are usually weaker. Bamboo in orthopedic application has been a center focus for developing country due to its low cost and availability.

In spite of the great progress made in the design and implementation of parallel-limb exoskeletons, there is room for further improvement, especially if low cost materials are to be considered. As part of an ongoing research in our laboratory on the use of natural materials for cost effective manufacturing, bamboo has been considered a replacement material for exoskeleton orthopedic device [3]. Bamboo's characteristic mechanical properties such as strength and toughness have made it a formidable infrastructural material. The normal stress of bamboo has been found to be similar of that to steel and concrete in compression. Therefore, it has found a wide variety of usage in different applications, which include furniture, flooring, roofing, bridges, buildings, etc. It is not surprising that bamboo has also been used as materials for rehabilitation appliances such as resting night splints, upper limb splints, canes, and walkers in developing countries [4]. The fact that it is a natural material that grows fast, readily available, low-cost, and renewable is additional attributes that make the material attractive for infrastructure and orthotic rehabilitation.

It has been documented that traditional bonesetters (TBS) in many parts of the developing world use bamboo for splinting fractures as a means of limb immobilization [5]. The treatment of fracture by TBS is an established practice and has been around for centuries in countries like Nigeria. A tradition usually introduced to the young generation by parents and grandparents, the practice of bone setting stretches across every strata of the society, to include the educated and rich alike [6]. Patients travel over hundreds of miles to attain this type of primitive care by the TBS. The high patronage given to the TBS by the natives is presumed to carry an economic, social, cultural, religious, and psychological undertone [7]. Although Bamboo splinting is an extensively culture-specific tradition for fracture treatment in the developing world [8], it is yet to be incorpo- 
rated into the mainstream practice in conventional hospitals due to a lack of standardization. The integration of bamboo into standard rehabilitation treatment in hospitals will require further research on the design and manufacturing of Bamboo. Thus, a comprehensive review of the current status of bamboo usage in infrastructure and orthopedics is required.

\section{Physical and Mechanical Properties of Bamboo}

The culm is the major part of the Bamboo plant that is used for numerous applications, these applications range from the simple natural form of the culm used in small thatch houses in the rural parts of some Asian and African countries to the more sophisticated engineered applications such as in fabrics, orthopedics, sports and transportation. The several alternatives in the utilization of the Bamboo depends on the exceptional physical and mechanical properties of the culm [9], which is influenced by its age, height, season and species. The mechanical properties of the culm are strongly related to its specific gravity (measure of the specific gravity of a substance in comparison to that of water), which decreases from the exterior to the interior part, and, increases from bottom to the top of the culm.

The strengths of the culm are greatly influenced by age and moisture content (MC\%) which varies within the culm. Liese also reported that the general assumption for the average maturity age for a Bamboo culm to exhibit its highest strength is about three to four years. The older culms have lower MC\% than the younger ones in the green or dry conditions. The compressive and bending strengths of the Bambusa Blumeana and Gigantochioa Levis species increase from the bottom to the top of the culms [9]. Gutu [10] compared the results of the strength tests carried out on spruce wood, Bamboo and steel. Table 1 shows comparatively the various mechanical properties of spruce wood, Bamboo and steel, all tests were carried out in accordance with the international standards.

Fabiani [11] investigated the Physical and mechanical properties of Italian bamboo culms for Phyllostachys Edulis and Phyllostachys Viridiglaucescens species. His result also showed that the average values for the compressive- $51 \mathrm{MPa}$, tensile-126 MPa and bending-97 MPa strengths were close to that of steel.

An analysis was carried out on various natural materials using Granta CES Edupack Selector software. Property comparison between four natural materials is presented in Table 2. It is evident that of all the natural materials considered, Bamboo displayed better properties which translate to its consideration for several applications especially in the area of prosthetics. The choice was reduced significantly when the toughness requirement was considered.

The fracture properties of the Bamboo culm are higher for the outer surface and decreases as you move towards the inner surface, this value is also higher at the culm of the bamboo and lower at its nodes. A fracture toughness test was carried for a two-year-old Phyllostachysedulis (Moso Bamboo) and the results showed an average value of $56.8 \mathrm{MPam}^{1 / 2}$ at the culm which is higher than that 
Table 1. Mechanical properties of some materials [10].

\begin{tabular}{cccc}
\hline \multirow{2}{*}{$\begin{array}{c}\text { Mechanical Properties } \\
(\mathrm{MPa})\end{array}$} & Spruce Wood & Materials & \\
\cline { 2 - 4 } & 43 & $62-93$ & Steel \\
\hline Compressive strength & 89 & 148 & 140 \\
Tensile strength & 68 & $76-276$ & 140 \\
Bending strength & & & 140 \\
\hline
\end{tabular}

Table 2. Physical and Mechanical properties of some natural materials compared with Bamboo [3].

\begin{tabular}{cccc}
\hline Materials & $\begin{array}{c}\text { Compressive } \\
\text { Strength } \sigma(\mathrm{MPa})\end{array}$ & $\begin{array}{c}\text { Young's Modulus E } \\
(\mathrm{GPa})\end{array}$ & $\begin{array}{c}\text { Density } \rho \\
\left(\mathrm{g} / \mathrm{cm}^{3}\right)\end{array}$ \\
\hline Fir & $30.7-33.8$ & $5.9-6.7$ & $0.31-0.34$ \\
Pine & $34.0-41.6$ & $6.5-8.8$ & $0.35-0.42$ \\
Oak & $47.7-74.9$ & $7.9-12.4$ & $0.53-0.61$ \\
Bamboo & $140-230$ & $11-17$ & $0.6-1.1$ \\
\hline
\end{tabular}

of Aluminum alloy and far higher than other woods, and, an average value of 18.4 $\mathrm{MPam}^{1 / 2}$ at the node [12].

Bending natural materials into their desired shape is considered a measure of formability. Formability is the ability of a material to undergo permanent deformation without being damaged. In addition to other physical and mechanical properties of materials, it is important to also consider their formability in certain areas of applications such as in construction that requires complex forming of various shapes. There are three main bending techniques used for natural materials: laminating, heating, and kerfing [13]. Heating encompasses a variety of processes but the most common one being steam bending, in which the wood is put in a steam box to soften [13] [14]. The heating process is the lengthiest process but produces flexible and stronger curves. Kerfing, the last of the three bending processes, involves cutting a series of slits into the wood to allow bending [13]. Although kerfing is the quickest approach, it leaves the wood in a much weaker condition. Bending with heat is the best method to form natural materials into their desired bent shape, as it doesn't weaken the material drastically and avoids altering the state of the material. Bending with heat is typically used on hardwood materials, such as bamboo and oak, as they possess high bending quality, whereas softwoods, such as fir and pine, possess low bending quality. Oak can be bent with the steam bending process whereas bamboo is bent using a heat source such as a torch [15].

Figure 1 shows bamboo used in furniture after it has undergone the heat bending process [13]. 


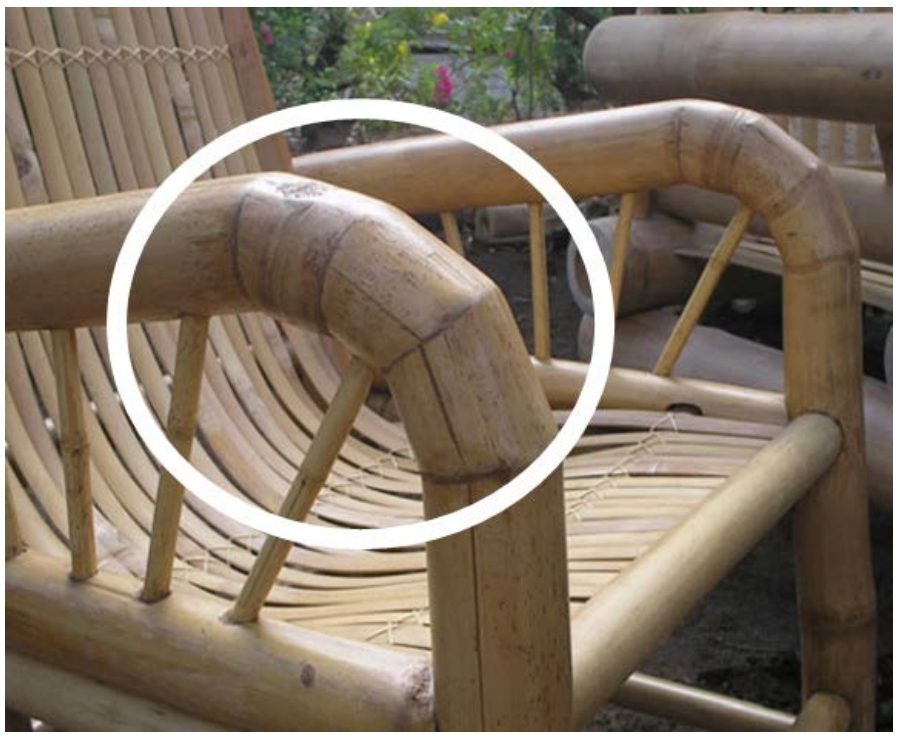

Figure 1. Bamboo chair that utilized the heat bending process [13].

\section{Some Applications of Bamboo in Its Natural form}

\subsection{Bamboo as Infrastructure Material}

In order to increase the self-sufficiency of most developing countries in Africa and Asia, indigenous materials such as Bamboo plant were exploited in the past [16]. There is also a renewed interest in bamboo in developed countries and this appears to correlate with the eco-friendly sustainability movement in materials and technology. Farmers are now planting bamboo in vast acres of land, even in the USA. A local bamboo farm is located in Monticello near the Tallahassee area. The farm specializes in the growing Moso Bamboo (Phyllostachysedulis).

Bamboo is often regarded as one of the foremost natural material used in building and other constructional works. Bambusa Pervariabilis (Clumper Bamboo) and Phyllostachys Pubescens (runner Bamboo) are the commonest species of Bamboo used in scaffolding in the south eastern part of China [17]. Chung and $\mathrm{Yu}$ [17] also reported that both species of Bamboo are good constructional material exhibiting excellent mechanical properties against compression and bending. For cost effectiveness and easy construction of scaffolds, construction experts are advised and encouraged to utilize these excellent properties of the Bamboo plant. Figure 2 and Figure 3 show typical scaffolds built with Bamboo.

Many low-rise, bridges and span roof long span roofs have been constructed in countries where is Bamboo is largely grown. In 1937, the United States army in the Philippines designed a bridge using Bamboo [17]. The bridge spanned up to $15 \mathrm{~m}$ and was able to withstand a load of 16 kilo-newton. In recent times, bridges have been built using laminated Bamboo technology. In 2006, the first model Bamboo bridge was built as a way to try out the use of the laminated bamboo. Xiao reported that a prototype of girder specimens made from Bamboo were manufactured and used in constructing a $10 \mathrm{~m}$ long pedestrian bridge in 


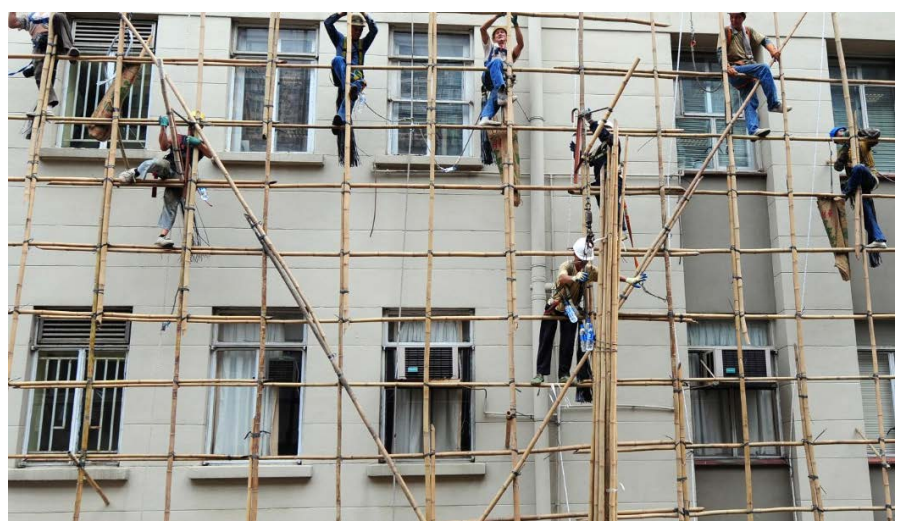

Figure 2. Bamboo scaffolding [20].

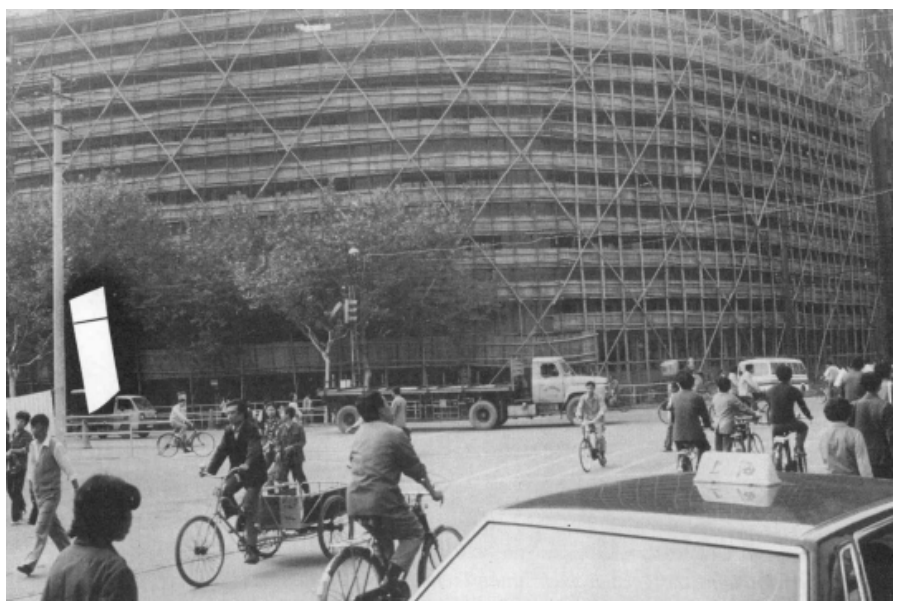

Figure 3. Bamboo scaffolding in Shanghai in 1985 [21].

Daozi, the surface of the bridge was covered with precast concrete made from reinforced bamboo strip [18]. Figure 4 shows a girder Bamboo specimen and the pedestrian bridge built with it. Key structural element such as slabs, walls, columns and beams has been manufactured using Bamboo (Bamboo reinforced concrete). Shweta and Shruti reported that a properly treated Bamboo culm can withstand up to $3656 \mathrm{~kg} / \mathrm{cm}^{2}$ of pressure supporting its use as a highly resilient material against forces created by high velocity winds and earthquake [19].

Bamboo culm has offered distinctive prospect for mass housing while actively contributing to the eco-restoration, carbon credits and livelihoods of the disadvantaged rural communities [22]. Also, Bamboo culm has been used in the past for building purposes because of its high strength to weight ratio. With the increasing population, shortage of housing infrastructure and the high cost of other building and construction materials in developing countries, people have resorted to using other cheaper and readily available materials for building houses. Medium-sized families in the rural parts of Japan, China, India and the Philippines have extensively utilized the Bamboo plant in building houses [23] (Figure 5(a)). More sophisticated buildings have been constructed using Bamboo in parts of north America (Figure 5(b)). 

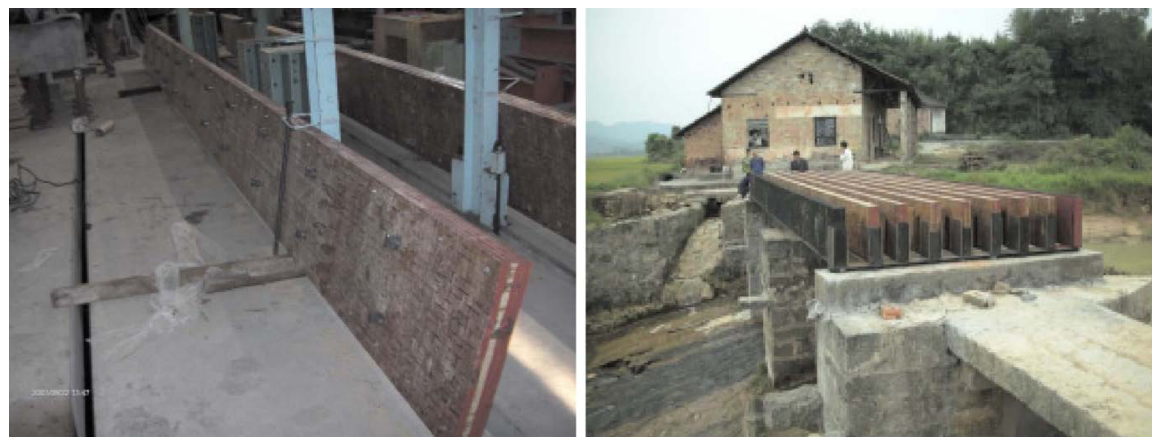

Figure 4. Laminated Bamboo girders [18].

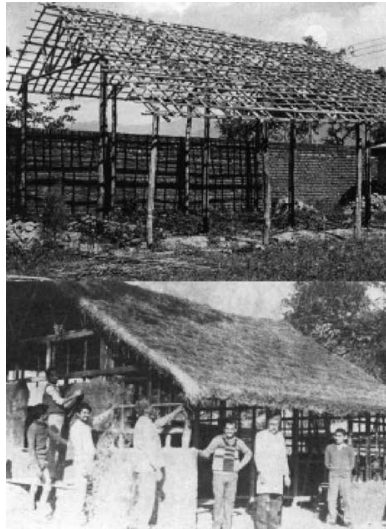

(a)

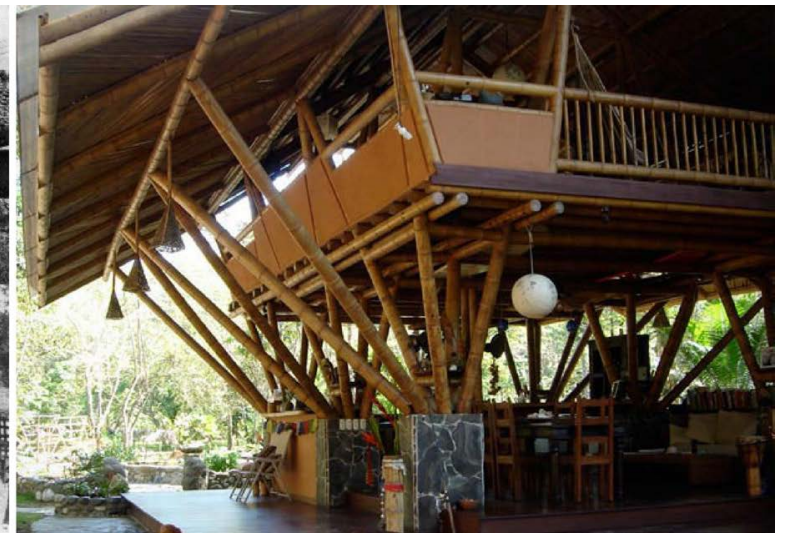

(b)

Figure 5. (a) Bamboo houses showing roof covered with thatches [23] (b) Modern Bamboo house build by Architect Mariela Garcia in Costa Rica [24].

\subsection{Bamboo Usage in Transportation}

Across some regions in east Africa, millions of people especially farmers are faced with lack of transportation due the high cost of acquiring either a bicycle or a car. This has often led to low income resulting from the inability of the farmers to transport their farm produce to the market. These economic and other climates related challenges such as carbon emission has prompted the exploitation and utilization of alternative means of transportation. For instance, Ugandans are currently working on the use of Bamboo to design bicycles and tricycles for farmers that will foster economic growth and mobility, nurture productivity, reduce carbon emission and also reduce poverty [25]. As cities get bigger and richer, the acquisition of cars increases, hence overpopulated areas in parts of Asia are encouraging her citizens to use other means of transportations including bicycle [26]. For this reason, bicycle lanes were created, and mobile bike repairman were stationed at every corner. The Bamboo culm is as strong as steel, thus making it a viable candidate for designing the frames of the bicycle (Figure 6).

Bamboo could pose as the next carbon fiber. Although carbon fiber has proven to be a stronger material, Bamboo parts also come in with a few advantages over carbon fiber. For a lighter and low environmental impact application, 
Bamboo serves as an alternative material. Taxis (Figure 7) which are fully $90 \%$ Bamboo are now used in the Philippines, the construction may not be sophisticated, but this is a move to further justify the importance of Bamboo.

Although there are drawbacks associated with the use of Bamboo which includes validation based on the theories of mechanics, materials, design of structure and proper testing, and, the lack of support from regulatory agencies [18], the main idea is to exploit alternative materials other than aluminum and ferrous alloys for applications where weight and environmental impact are considered [28].

\subsection{Bamboo in Orthopedic Practice}

Probably the single most important issue facing the developing countries and the various agencies, which attempt to help them in the rehabilitation of the amputee, is that of "appropriate technology". There is evidence that many of the artificial limbs supplied in the developing world do not function in the manner intended [30]. This may be due to poor design, the use of inappropriate materials, or to poor fit and alignment. It is interesting to note that many will remain serviceable for only two or three years and many prosthetics will not last for more than six months [31]. It is therefore not surprising that some developing countries have adopted the use of bamboo in orthopedic practice to continue to function and maintain a degree of quality of life, such as the pole leg or the bamboo/plaster leg. Unfortunately, the adoption of using pieces of bamboo cut into

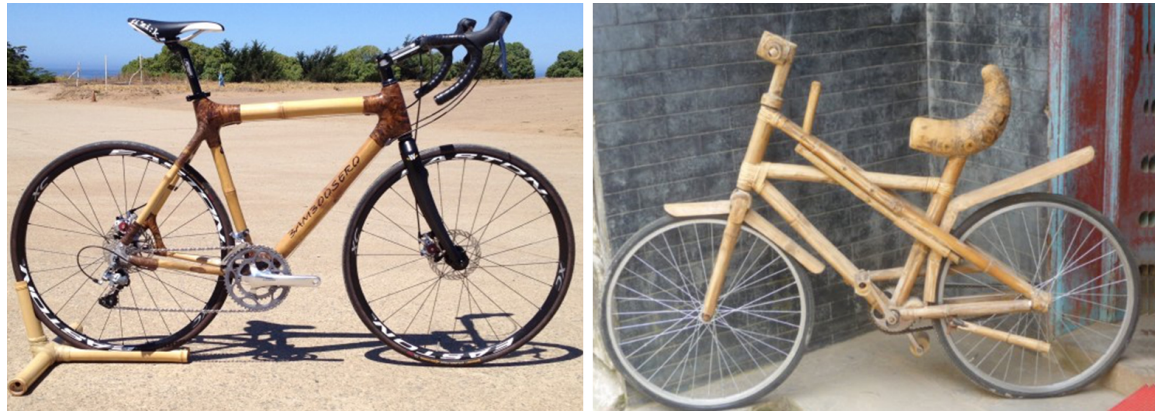

Figure 6. Bicycle frames made from Bamboo [27].

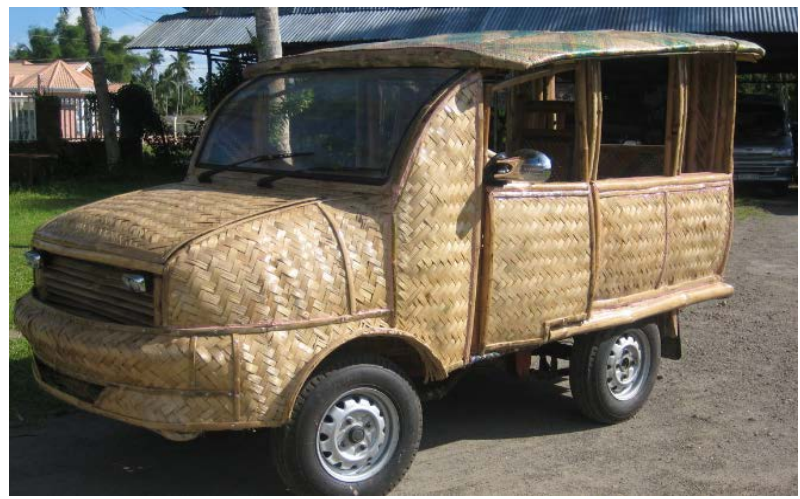

Figure 7. Bamboo taxi [29]. 
long narrow pieces and attached to the socket with a thin wire is often defined primitive or crude technology [30]. More sophisticated designs should entail the application of the best that can be done with the resources of equipment, staff, materials and finances available to prevent contractures and restore function. In general, the level and standard of prosthetic supply is a matter of national economic, social conscience and demand driven by patients and the medical profession. In the developing world, the care of patients is more complex. When applied to prosthetics the material and technology must satisfy accepted biomechanical and functional principles to address long term fitting problems [31]. In developing countries those who are injured or who suffer an acute surgical emergency are far from sophisticated hospital facilities [32].

Over three million people in the developing world require a prosthesis [33]. The use of bamboo stick is widely employed to construct several low-cost orthotic appliances to include: the cock-up splint, Volkmann's splint, intrinsic plus splint, ankle-foot orthosis, knee-ankle-foot orthosis, and the hip-knee-ankle-foot orthosis related to availability, accessibility, affordability, and acceptability [4]. Over 250 orthotic night splints, 100 cock-up splints, 20 Volkmann's splints and approximately 10 intrinsic plus splints have been constructed out of flat pieces of bamboo for patients to improve biomechanical function at the joint [4]. Construction time, weight, and cost were shown to be advantageous in bamboo's use for fabricating a number of low-cost orthotic appliances; however, the use of these native fracture splints carries an acquired risk. Bamboo usage in orthopedic devices can be classified into three categories based on the complexity of the manufacturing.

\subsubsection{Bamboo as a Low Technical Orthopedic Device Casts and Splints}

In the developing world, bamboo has been used extensively as native night splints and upper limb splints by traditional bonesetters (TBS) to protect injured bones. Requiring little or no structural modification to fabricate basic casts or splints, bamboo has become a viable alternative and low-cost material in simple orthotic appliance creation in rural areas of the developing world [34]; particularly where access to proper healthcare is often limited.

Fracture management by the TBS often involves the use of flat pieces of bamboo portions applied to the individual at the site of injury. The bamboo is fixed to the injured extremity with twine, straps of leather or Velcro at strategic holding points over the fractured or injured limb as shown in Figure 8. When applied correctly, this method of bamboo splinting was evidenced to provide appropriate fracture stabilization but often tightly bound application around the limb can lead to complications and resultant limb amputation.

Cultural practices hold high influence in the traditional management of fractures for care of the injured in developing worlds. Consequently, ancestral heritage and secretive family practices primarily represent the skill and training held by many TBS [6]. Variations in practitioner training methods and lack of man- 
agement standardizations by traditional bone setters, extremity gangrene necessitating amputation is a common problem evidenced in the literature linked to tight splinting around the joint [5] [35]. A common complication known as, traditional bone setter's gangrene (TBSG) is often seen following native fracture splint mismanagement of reasonably simple closed fracture [8]. Tight splinting practices by traditional healers can go unkempt over the course of weeks or days triggering major complications that can lead to limb amputations [5]. Figure 9 depicts an extremity gangrene in a musculoskeletal injury associated with TBS intervention and management.

A prospective study conducted by Onuminya examined over a 3-year period the management of the complications of the TBS treatment of limb fractures [35]. The author's findings showed that tight application methods of native bamboo fracture splint treatment lead to TBSG complications in twenty-five of the reported twenty-five cases [35]. Additionally, 15 of the 25 cases required amputation resulting from major complications of severe tissue lost, exposed necrotic bones and wound sepsis that necessitated the need for amputation [35]. Eshete published a two-year retrospective study that looked at the number of gangrenous limbs requiring amputation in southern Ethiopia [5]. The author found that 25 of the 49 amputations performed in southern Ethiopia were linked to complications following tight splint applications by TBS [5].

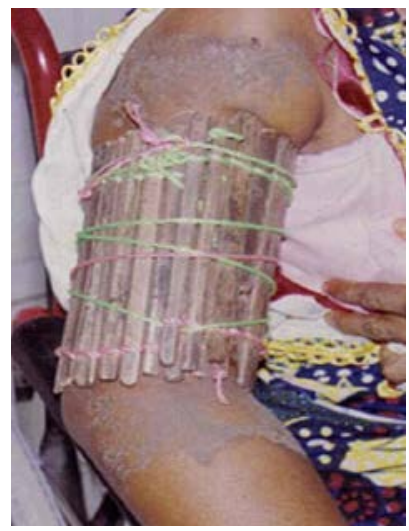

Figure 8. A picture of a typical arm splinting using bamboo [6].

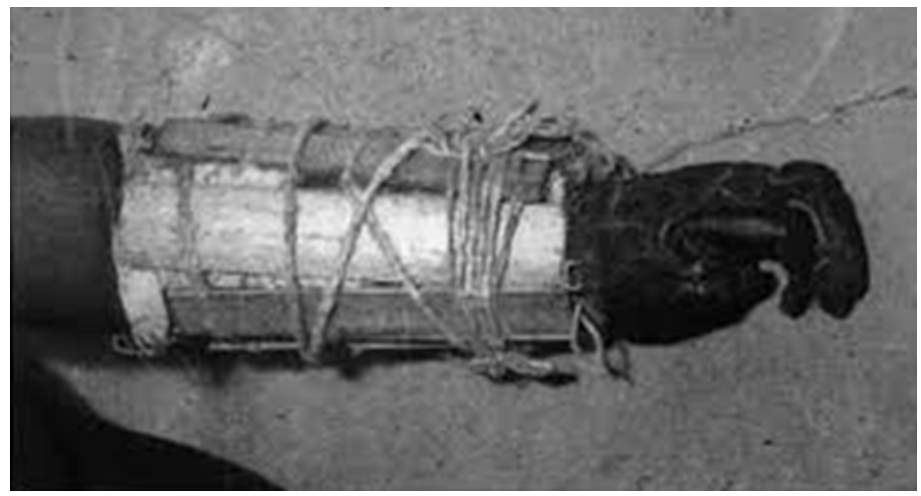

Figure 9. Complications of the TBS treatment of limb fractures [5] [8]. 
There is need to educate and train traditional bonesetters in effective management of acute trauma musculoskeletal injuries to minimize frequently seen complications in the routine treatment of bamboo splinting method, and to institute consistency to improve cultural practices [36].

\subsubsection{Bamboo as a Mid-Technical Orthopedic Device}

\section{Canes, Crutches, and Walkers}

Bamboo has been altered or modified in shape to some degree through bending and forging the material. In manufacturing certain rehabilitation aids from bamboo, the bamboo is heated to create the necessary structural design or bend important for the orthopedic appliance. The heat is applied at a rate that allows the bamboo to become pliable enough to create the desired bend or shape for standard fabrication or tailored design of the rehabilitation aid to address the need of the patient. As previously mentioned, the strength of the bamboo is not altered at the point of bending [4]; therefore, bamboo's mechanical properties have been shown to be suitable to provide effective supportive weight bearing to improve the patient's function.

Banerji and Banerji discussed the usefulness of bamboo as a basic construction material for walkers, and crutches secondary to its characteristic high pliability and malleability qualities [4]. Suwannarat found out that $22 \%$ elderly Taiwanese people utilized modified walking sticks made from bamboo to improve general ambulation quality and walking capacity [37]. For these reasons, bamboo was found to be an ideal material for making orthotic and prosthetic appliances, especially since its strength is not altered following bending or forging treatment applications. Hence, it is vital that appliances from locally available materials must be simple and inexpensive and should be such as to need only minimal maintenance and low costs [32]. Some examples of walking sticks made from bamboo are shown in Figure 10.

Although the use of Bamboo for Prostheses is still under experimental investigation, its application in below and above-kneel prosthesis is of great importance. In below-kneel (Figure 11) application, this prosthesis is of endoskeleton type having a patellar-bearing top with a Jaipur foot as base and a cane connecting the structure [4]. For the above-kneel application (Figure 12), there is a weight-bearing brim made of cane and a woven cane basket which is padded below the cane, a simple belt and elastic straps are used as a suspension system. The advantages of using Bamboo for this application are connected to its lightness.

\subsubsection{Bamboo as a High Technical Orthopedic Device Prosthesis and Exoskeleton}

The bamboo has been modified using advanced engineering design and technology for state-of-the-art devices. Prostheses should be developed for function; whereby, the prosthesis must satisfy accepted biomechanical and functional principles [31]. From the times of the ancient Egyptians to that of French 


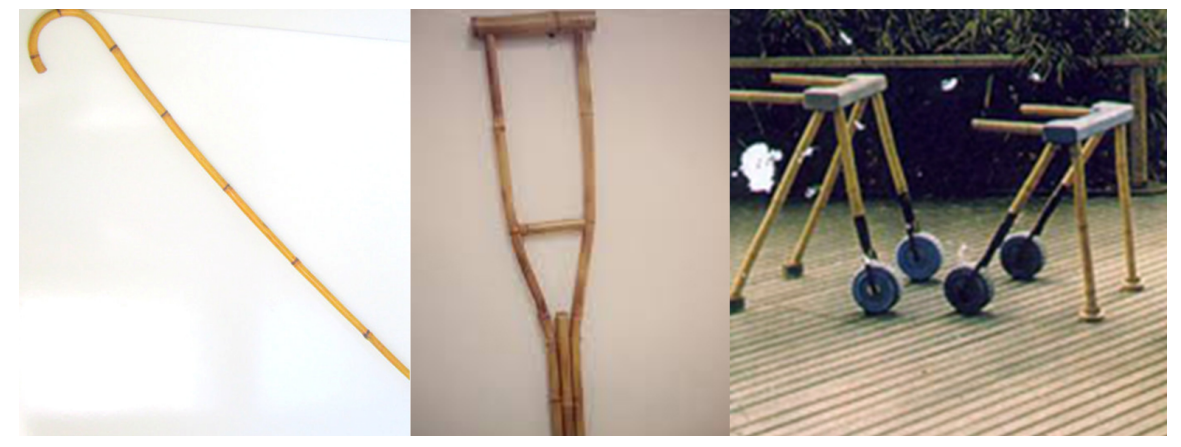

Figure 10. Crutches, Cane and Walkers made from Bamboo.

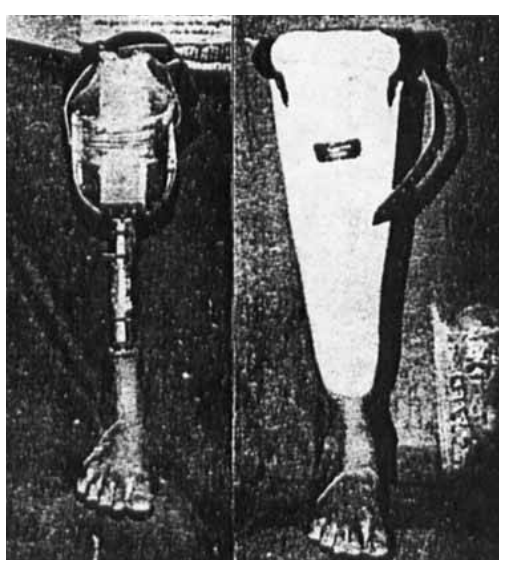

Figure 11. Bamboo endoskeleton patellar-tendon-bearing prosthesis [4].

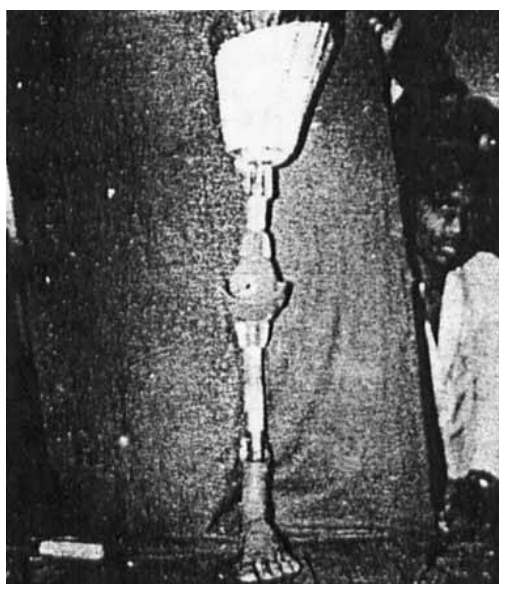

Figure 12. Bamboo above-knee prosthesis with coco-nut knee joint [4].

surgeon, Ambroise Pare'; the crafting of artificial limbs was made to help people compensate for the loss of a limb [38]. For example, motorization of wheelchairs through computer-aided drawing (CAD), computer-aided manufacturing (CAM), machining processes, or mechanical testing has been utilized in the design and development of these high-tech devices. Figure 13 shows a wheelchair made from bamboo. 


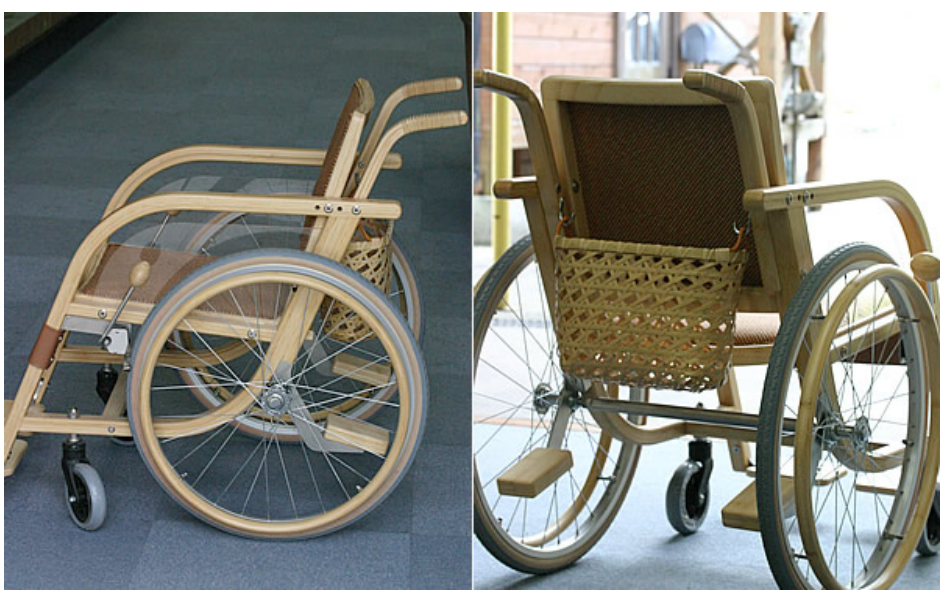

Figure 13. Wheelchairs made of bamboo [39].

Bamboo has not transitioned into the high-tech area yet, however, it is the intention of this review to see how bamboo can be used for this intended purpose. The authors intend to introduce bamboo to high-tech orthopedics through exoskeleton.

\section{Some Applications of Bamboo in Its Engineered Form}

Bamboo has been engineered into different forms and used areas where high load bearing strength is not required. Some of these areas include Automotive industry for designing of steering wheels, sports bicycle, surfboards, electronics industry for the manufacture of phone cases, farming industry and sports. Some examples of the engineered form of bamboo is shown in Figure 14.

When Bamboo fiber is used with polymeric resin, a biocomposite material is formed, this area of composite engineering has attracted the interest of materials scientists, researchers and manufacturing industries on the account of the mechanical and physical properties of the final product obtained. Scrimber and laminated sheets (shown in Figure 15) have been made from Bamboo and the studies conducted showed that the engineered Bamboo products have properties that surpass those of timber and timber based-products [41].

\section{Conclusion}

This review focused on the usage of bamboo in both its natural and engineered form. Bamboo has shown to have mechanical properties compared to wood and other ferrous metals such as steel. This has forced its use in various applications ranging from construction of thatch houses and fences to more sophisticated application such as scrimbers and laminates. It is also important to note that bamboo has been used extensively in developing countries as night splints and upper limb splints but not for lower limb orthoses and prosthesis. While bamboo usage in orthopedic appliances appears to be promising, the expansion into mainstream orthopedic rehabilitation is hampered due to a lack of standardization on comprehensive mechanical property data. 

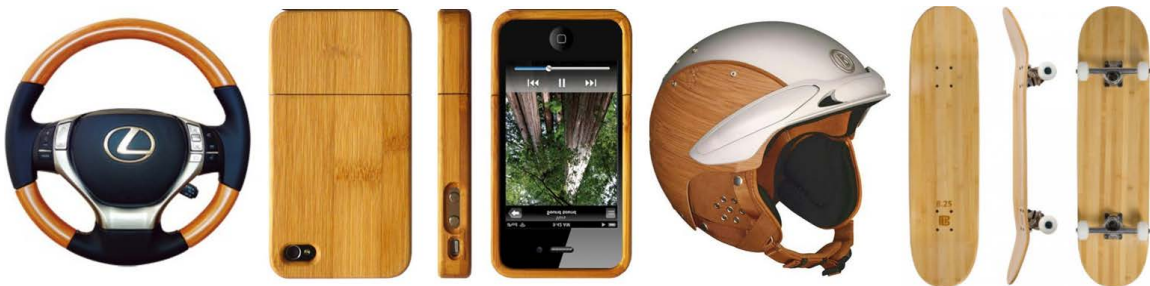

Figure 14. Some applications of Bamboo in its engineered form [40].

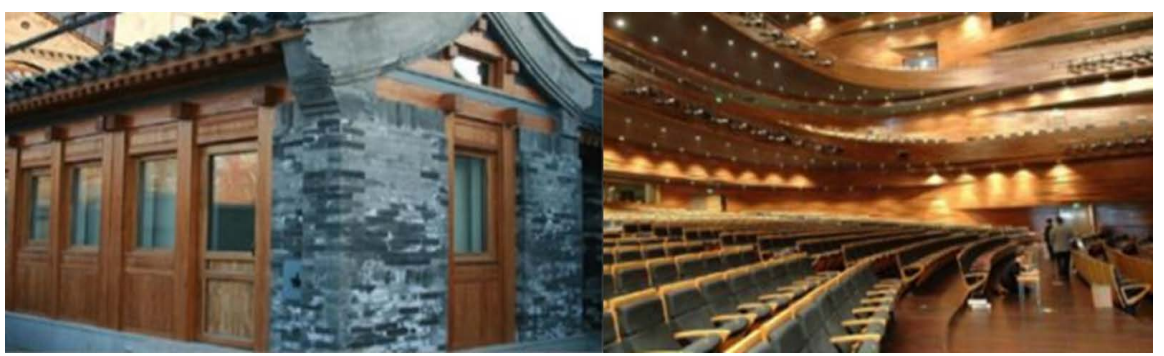

Figure 15. Bamboo Scrimber used in windows, windows and interior decoration [42].

\section{Conflicts of Interest}

The authors declare no conflicts of interest regarding the publication of this paper.

\section{References}

[1] Gupta, D. and Ranjan, R. (2016) Role of Bamboo in Sustainable Development. International Journal of Advances in Scientific Research, 2, 25-32.

[2] Tamang, D.K., Dhakal, D., Gurung, S., Sharma, N.P. and Shrestha, D.G. (2013) Bamboo Diversity, Distribution Pattern and Its Uses in Sikkim (India) Himalaya. International Journal of Scientific and Research Publications, 3, 1-6.

[3] Reed, K. and Kalu, P. (2016) An Assessment of Bamboo as a Potential Low-Cost Material for Exoskeleton Design in Normal Walking. International Journal of Physical Therapy \& Rehabilitation, 2, 111. https://doi.org/10.15344/2455-7498/2016/111

[4] Banerji, B. and Banerji, J.B. (1984) A Preliminary Report on the Use of Cane and Bamboo as Basic Construction Materials for Orthotic and Prosthetic Appliances. Prosthetics and Orthotics International, 8, 91-96. https://doi.org/10.3109/03093648409145355

[5] Eshete, M. and Surgery, R. (2005) The Prevention of Traditional Bone Setter's Gangrene General Orthopaedics. The Journal of Bone and Joint Surgery, 87, 102-103. https://doi.org/10.1302/0301-620X.87B1.15585

[6] Dada, A.A., Yinusa, W. and Giwa, S.O. (2011) Review of the Practice of Traditional Bone Setting in Nigeria. African Health Sciences, 11, 262-265.

[7] Alam, W., Shah, F.A., Ahmed, A., Ahmad, S. and Shah, A. (2016) Traditional Bonesetters; Frequency of Complications with Treatment by Traditional Bonesetters. The Professional Medical Journal, 23, 699-704. https://doi.org/10.17957/TPMJ/16.3354

[8] Onuminya, J.E. (2006) Performance of a Trained Traditional Bonesetter in Primary Fracture Care. South African Medical Journal, 96, 320-322.

[9] Rao, A.N., Dhanarajan, G. and Sastry, C.B. (1985) Recent Research on Bamboos on 
Bamnoos. Chinese Academy of Forestry, Beijing.

[10] Gutu, T. (2013) A Study on the Mechanical Strength Properties of Bamboo to Enhance Its Diversification on Its Utilization. International Journal of Innovative Technology and Exploring Engineering, 2, 314-319.

[11] Fabiani, M. (2015) Physical and Mechanical Properties of Italian Bamboo Culms.

[12] Amada, S. and Untao, S. (2001) Fracture Properties of Bamboo. Composites Part B: Engineering, 32, 451-459. https://doi.org/10.1016/S1359-8368(01)00022-1

[13] How to Bend Bamboo-Guadua Bamboo. https://www.guaduabamboo.com/

[14] Home | Learn Steam Bending. https://www.learnsteambending.com/steam-bending

[15] How to Bend Bamboo for a Walking Cane. https://www.hunker.com/13425499/how-to-bend-bamboo-for-a-walking-cane

[16] Dhenesh Raj, A. and Agarwal, A.B. (2014) Bamboo as a Building Material. Journal of Civil Engineering and Environmental Technology, 1, 56-61.

[17] Chung, K.F. and Yu, W.K. (2002) Mechanical Properties of Structural Bamboo for Bamboo Scaffoldings. Engineering Structures, 24, 429-442. https://doi.org/10.1016/S0141-0296(01)00110-9

[18] Xiao, Y., Asce, M., Zhou, Q. and Shan, B. (2010) Design and Construction of Modern Bamboo Bridges. Journal of Bridge Engineering, 15, 533-541. https://doi.org/10.1061/(ASCE)BE.1943-5592.0000089

[19] Patil, S. and Mutkekar, S. (2014) Bamboo as a Cost Effective Building Material for Rural Construction. Journal of Civil Engineering and Environmental Technology, 1, 35-40.

[20] Hong Kong's Incredible Bamboo Spidermen-CNN Style. https://www.cnn.com/style/article/hong-kong-bamboo-spidermen/index.html

[21] Janssen, J.J.A. (2000) Designing and Building with Bamboo. International Network for Bamboo and Rattan, Beijing, p. 208 (Technical Report).

[22] Jit Kaur, P. (2018) Bamboo Availability and Utilization Potential as a Building Material. Forestry Research and Engineering: International Journal, 2, 240-242. https://doi.org/10.15406/freij.2018.02.00056

[23] Rao, I.R., Gnanaharan, R. and Sastry, C., Kerala Forest Research Institute \& International Development Research Centre (Canada) (1988) Bamboos-Current Research. Proceedings of the International Bamboo Workshop, Cochin, India.

[24] The Reality about Building with Bamboo-Guadua Bamboo. https://www.guaduabamboo.com/construction/the-reality-about-building-with-ba $\underline{\mathrm{mboo}}$

[25] Bamboo for Bicycles \& Transportation | Pacific Bamboo Resources. https://pacificbamboo.org/bamboo-for-good/b4b/

[26] Bamboo Bicycles Beijing. How Can We Empower Youth to Shape Their Own Mobility Culture?

[27] Booomers Bamboo Bikes. https://booomers.com/

[28] Could Renewable Bamboo Be as Strong as Carbon Fiber for Lightweight Cars? https://www.greencarreports.com/news/1092320_could-renewable-bamboo-be-as-s trong-as-carbon-fiber-for-lightweight-cars

[29] Biodiesel Bamboo Cabs: Philippines Town Turns Taxis Green. https://www.greencarreports.com/news/1043593_biodiesel-bamboo-cabs-philippine s-town-turns-taxis-green

[30] Strait, E. (2006) Prosthetics in Developing Countries. 
[31] Desmond, D. and Maclachlan, M. (2002) Psychological Issues in Prosthetic and Orthotic Practice: A 25-Year Review of Psychology. Prosthetics and Orthotics International, 26, 182-188.

[32] Weston, P.M. (1986) Simple Resources for Essential Surgery. Tropical Doctor, 16, 25-30. https://doi.org/10.1177/004947558601600110

[33] Cummings, D. (1996) Prosthetics in the Developing World: A Review of the Literature. Prosthetics and Orthotics International, 20, 51-60. https://doi.org/10.3109/03093649609164416

[34] Onuminya, J.E., Obekpa, P.O., Ihezue, H.C., Ukegbu, N.D. and Onabowale, B.O. (2000) Major Amputations in Nigeria: A Plea to Educate Traditional Bone Setters. Tropical Doctor, 30, 133-135. https://doi.org/10.1177/004947550003000306

[35] Onuminya, J.E., Onabowale, B.O., Obekpa, P.O. and Ihezue, C.H. (1999) Traditional Bone Setter's Gangrene. International Orthopaedics, 23, 111-112. https://doi.org/10.1007/s002640050320

[36] Omololu, A.B., Ogunlade, S.O. and Gopaldasani, V.K. (2008) The Practice of Traditional Bonesetting: Training Algorithm. Clinical Orthopaedics and Related Research, 466, Article No. 2392. https://doi.org/10.1007/s11999-008-0371-8

[37] Patcharawan, S., Thaweewannakij, T., Kaewsanmung, S., Kaewjoho, C., Saengsuwan, J. and Amatachaya, S. (2015) Walking Devices Used by the Elderly Living in Rural Areas of Thailand. Malaysian Journal of Medical Sciences, 22, 48-54. https://pubmed.ncbi.nlm.nih.gov/26023295/

[38] Hernigou, P., Homma, Y., Flouzat-Lachaniette, C.-H., Poignard, A., Chevallier, N. and Rouard, H. (2013) Cancer Risk Is Not Increased in Patients Treated for Orthopaedic Diseases with Autologous Bone Marrow Cell Concentrate. The Journal of Bone and Joint Surgery, 95, 2215-2221.

[39] Dogbatse, E.D. (2018) Ghana's Bamboo Wheelchairs; When Engineering Meets Indigenous Craft.

https://www.graphic.com.gh/features/opinion/ghana-s-bamboo-wheelchairs-whenengineering-meets-indigenous-craft.html

[40] Products Made from Bamboo. https://www.bambooimport.com/en/products-made-from-bamboo

[41] Sharma, B., Gatóo, A., Bock, M. and Ramage, M. (2015) Engineered Bamboo for Structural Applications. Construction and Building Materials, 81, 66-73. https://doi.org/10.1016/j.conbuildmat.2015.01.077

[42] Huang, Y.X., Ji, Y.H. and Yu, W.J. (2019) Development of Bamboo Scrimber: A Literature Review. Journal of Wood Science, 65, Article No. 25. https://doi.org/10.1186/s10086-019-1806-4 